\title{
Neonatal Exposure to Diethylstilbestrol Alters Expression of DNA Methyltransferases and Methylation of Genomic DNA in the Mouse Uterus
}

\author{
KOJI SATO*,**,***, HIDEKI FUKATA**,***, YASUSHI KOGO ${ }^{\#}$, JUN OHGANE\#, KUNIO SHIOTA ${ }^{\#}$ \\ AND CHISATO MORI*,**,***,\#\# \\ *Department of Bioenvironmental Medicine, Graduate School of Medicine, Chiba University, 1-8-1 Inohana, Chuo-ku, Chiba 260- \\ 8670, Japan \\ **Environmental Health Science Project for Future Generations, Graduate School of Medicine, Chiba University, Chiba 260-8670, \\ Japan \\ ***Center of Environmental Health Science for Future Generations (NPO), 1-8-1 Inohana, Chuo-ku, Chiba 260-8670, Japan \\ \#Laboratory of Cellular Biochemistry, Animal Resource Science/Veterinary Medical Sciences, Graduate School of Agriculture and \\ Life Science, The University of Tokyo, 1-1-1 Yayoi, Bunkyo-ku, Tokyo 113-8657, Japan \\ \#Center for Environment, Health and Field Sciences, Chiba University, 6-2-1 Kashiwanoha, Kashiwa 277-0882, Japan
}

\begin{abstract}
Perinatal exposure to diethylstilbestrol (DES) can have numerous adverse effects on the reproductive organs later in life, such as vaginal clear-cell adenocarcinoma. Epigenetic processes including DNA methylation may be involved in the mechanisms. We subcutaneously injected DES to neonatal C57BL/6 mice. At days 5, 14, and 30, expressions of DNA methyltransferases (Dnmts) Dnmt1, Dnmt3a, and Dnmt3b, and transcription factors Sp1 and Sp3 were examined. We also performed restriction landmark genomic scanning (RLGS) to detect aberrant DNA methylation. Real-time RTPCR revealed that expressions of Dnmt1, Dnmt3b, and Sp3 were decreased at day 5 in DES-treated mice, and that those of Dnmt1, Dnmt3a, and Sp1 were also decreased at day 14. RLGS analysis revealed that 5 genomic loci were demethylated, and 5 other loci were methylated by DES treatment. Two loci were cloned, and differential DNA methylation was quantified. Our results indicated that DES altered the expression levels of Dnmts and DNA methylation.
\end{abstract}

Key words: DNA methylation, Epigenetics, Uterus, Diethylstilbestrol, Endocrine disruptor

(Endocrine Journal 56: 131-139, 2009)

DIETHYLSTILBESTROL (DES) is a synthetic nonsteroidal estrogen that was widely used to prevent miscarriage and other pregnancy complications from the late 1930s through the 1970s. In 1971, a correlation between DES exposure of mothers and the occurrence of vaginal clear cell adenocarcinoma in their young daughters was reported [1]. Subsequently, many other problems relating to female and male reproductive

Received: August 28, 2008

Accepted: October 20, 2008

Correspondence to: Chisato MORI, M.D., D.Med.Sci., Department of Bioenvironmental Medicine, Graduate School of Medicine, Chiba University, 1-8-1 Inohana, Chuo-ku, Chiba 2608670, Japan organs such as breast cancer, squamous neoplasia of the cervix and vagina, and prostate and testicular cancers have been reported [2]. An animal perinatal exposure model showed that DES induced similar reproductive abnormalities [3-5], and DES is now widely known as an estrogenic endocrine disruptor. In our previous studies, we showed that mice treated neonatally with DES or the phytoestrogen, genistein, developed altered expression levels of various genes in male reproductive organs, even during adulthood [610]. Since the expression changes lasted for long periods of time, and DES was reported to be non-genotoxic [11], epigenetic mechanisms might be involved in the gene expression changes. DNA methylation has an important role in epigenetics, and the DNA methy- 
lation of promoter regions generally represses gene expression. The cell specific DNA methylation patterns formed during development and differentiation are thought to be associated with cell specific gene expression patterns and cell characterization $[12,13]$. Li et al. reported that, in the uterus of mice treated neonatally with DES, DNA methylation of $\mathrm{CpG}$ sites in the lactoferrin gene promoter was altered [14]; and expression of c-fos was persistently elevated and $\mathrm{CpG}$ sites in its exon 4 were hypomethylated [15]. Alworth et al. reported that fetal exposure to DES caused changes in uterine weight and hypermethylation of ribosomal DNA at 7-8 months of age [16]. However, the mechanisms altering DNA methylation are unknown, and further information on aberrant DNA methylation of other genes including high-throughput analysis is required. Methylation of genomic DNA is catalyzed by DNA methyltransferases (Dnmts) including Dnmt1, Dnmt3a, and Dnmt3b. Dnmt1 is known as a maintenance methyltransferase responsible for copying the parental-strand methylation pattern to a daughter strand after DNA replication [17]. Dnmt3a and Dnmt3b function primarily as de novo methyltransferases to establish methylation patterns, and are strongly expressed in differentiating cells such as early embryos and developing germ cells [18]. In reports showing that environmental stresses (dioxin or Xirradiation) altered DNA methylation, expressions of Dnmts or methyltransferase activity were also altered $[19,20]$. Changes in expression levels of Dnmts may result in aberrant DNA methylation. Expression of Dnmts is thought to be regulated by complex mechanisms in a cell type or a differentiation stage specific manner, and transcription factors $\mathrm{Sp} 1$ and $\mathrm{Sp} 3$ are reported to participate in this process [21, 22]. Sp1 and Sp3 share the same binding sites, and competitively or cooperatively regulate expressions of various genes [23]. Altered expression of Dnmts induced by environmental stresses might be mediated by altered expression of $\mathrm{Sp} 1$ and/or Sp3.

In the present study to investigate effects of neonatal DES exposure on DNA methylation in the uterus, we analyzed expressions of Dnmts and related transcription factors as well as genome-wide DNA methylation. Real-time RT-PCR analysis revealed expression changes of Dnmts and transcription factors Sp1 and Sp3. Furthermore, genome-wide analysis of DNA methylation using restriction landmark genomic scanning (RLGS) revealed that several genomic loci were methylated or demethylated by neonatal DES exposure.

\section{Materials and Methods}

\section{Animals}

Pregnant C57BL/6 mice were obtained from Japan SLC (Shizuoka, Japan). Newborn mice were subcutaneously injected with DES dissolved in $25 \mu$ l sesame oil $(3 \mu \mathrm{g} / \mathrm{pup} /$ day $)$ from postnatal days 1 to 5 [4, 24, 25]. Untreated and vehicle-treated mice were used as controls. At days 5, 14, and 30, uteri were excised and stored at $-80^{\circ} \mathrm{C}$ until use. All mice were maintained in accordance with the Chiba University guidelines for animal experimentation.

\section{Real-time RT-PCR}

Total RNA was separately extracted from uteri of 5 mice using the TRIzol reagent (Invitrogen, San Diego, CA). Total RNAs were reverse-transcribed using the QuantiTect Reverse Transcription Kit (Qiagen KK, Tokyo, Japan) according to the manufacturer's protocols. Real-time RT-PCR was performed in a DNA Engine Opticon (MJ Research, Cambridge, MA) using the Platinum SYBR Green qPCR SuperMix UDG (Invitrogen). Primers for Dnmts [26] and other primers used in this study were as follows. Dnmt1 (Accession no. X14805): forward primer, 5'-CCT AGT TCC GTG GCT ACG AGG AGA A-3'; reverse primer, 5'TCT CTC TCC TCT GCA GCC GAC TCA-3'; Dnmt3a (Accession no. AF068625): forward primer, 5'-GCC GAA TTG TGT CTT GGT GGA TGA CA-3'; reverse primer, 5'-CCT GGT GGA ATG CAC TGC AGA AGG A-3'; Dnmt3b (Accession no. AF068626): forward primer, 5'-TTC AGT GAC CAG TCC TCA GAC ACG AA-3'; reverse primer, 5'-TCA GAA GGC TGG AGA CCT CCC TCT T-3'; Sp1 (Accession no. AF022363): forward primer, 5'-AGG GAG GCC CAG GTG TAG-3'; reverse primer, 5'-GGC AAG ACG GGC AAT ACC-3'; Sp3 (Accession no. BC079874): forward primer, 5'-TAC TCG CCT CTG GAA CAC CT-3'; reverse primer, 5'-GCA GAC CAA GAG GCA CAT TAG-3'; $\beta$-actin (Accession no. X03672): forward primer, 5'-AGA GGG AAA TCG TGC GTG AC-3'; reverse primer, 5'-CAA TAG TGA TGA CCT GGC CGT-3'. In all cases, reactions were performed 
in triplicate using the same five independent samples of uterine RNA. Real-time RT-PCR results were normalized against corresponding $\beta$-actin contents. Data were presented as means \pm S.E.M.

\section{$R L G S$}

RLGS was performed as described previously [2729]. Briefly, genomic DNA was extracted from control or DES-treated mice, and $3 \mu \mathrm{g}$ genomic DNA was treated with $10 \mathrm{U}$ Klenow fragment (Takara Bio, Shiga, Japan) in the presence of $0.4 \mu \mathrm{M} d G T P \alpha S$, $0.2 \mu \mathrm{M}$ dCTP $\alpha \mathrm{S}$ (Amersham Biosciences, Buckinghamshire, UK), $0.4 \mu \mathrm{M}$ ddATP, and $0.4 \mu \mathrm{M}$ ddTTP (Takara Bio). DNA was digested with $20 \mathrm{U}$ Not I as a methylation-sensitive landmark enzyme (Nippon Gene, Toyama, Japan), and cohesive ends were labeled with $1.3 \mathrm{U}$ Sequenase Version 2.0 (USB, Cleveland, $\mathrm{OH})$, in the presence of $0.33 \mu \mathrm{M}[\alpha-$ $\left.{ }^{32} \mathrm{P}\right] \mathrm{dCTP}$ and $0.33 \mu \mathrm{M}\left[\alpha_{-}{ }^{32} \mathrm{P}\right] \mathrm{dGTP}$ (Amersham Biosciences). The labeled DNA was then digested with $20 \mathrm{U} P v u$ II (methylation-insensitive, Nippon Gene), and was subjected to first-dimension electrophoresis on a $0.9 \%$ agarose gel at $230 \mathrm{~V}$ for $23 \mathrm{~h}$. DNA fragments in the gel were treated with $1000 \mathrm{U}$ Pst I (methylation-insensitive, Nippon Gene). Seconddimension electrophoresis was carried out at $160 \mathrm{~V}$ for $20 \mathrm{~h}$. The gel was then dried, and exposed to an X-ray film (Kodak, XAR 5, Eastman Kodak, Rochester, NY) for 2-4 weeks at $-80^{\circ} \mathrm{C}$. All experiments were repeated at least twice.

\section{Spot cloning}

Two spots in the uterus of DES-treated mice were cloned using Easy Anchor Not I (Nippon Gene). Briefly, genomic DNA from the uterus was digested with $N o t$ I and $P v u$ II. DNA fragments containing Not I ends were collected using Easy Anchor Not I. Onefifth of the purified DNA was labeled at the Not I site with $\left[\alpha-{ }^{32} \mathrm{P}\right] \mathrm{dGTP}$ and $\left[\alpha-{ }^{32} \mathrm{P}\right] \mathrm{dCTP}$ and the labeled portion mixed with the remaining four-fifths before being subjected to RLGS separation. After exposure to X-ray film for 1 week, gel pieces were punched out at specific spots. The DNA fragment in each punchedout gel spot was electro-eluted. The eluted DNA was initially ligated into the Not I and Pst I sites of pBluescript II (Stratagene, La Jolla, CA). Inserted fragments were amplified by PCR and the PCR products cloned into pGEM-T easy vectors (Promega, Madison, WI). Sequences were determined using an ABI PRISM 310 Genetic Analyzer (Applied Biosystems, Foster City, CA).

Quantification of DNA methylation at landmark Not I sites

Cloned DNA fragments from RLGS spots had one Not I site and one Pst I site at each end. To obtain methylation ratios of Not I sites of cloned spots, we conducted methylation-sensitive restriction digestion and real-time PCR. Genomic DNAs extracted from DES-treated and control mice were digested with methylation-insensitive Pst I. Subsequently, each sample was divided in half. One half was digested with methylation-sensitive Not I, and the other was not digested. Not I-treated and untreated DNAs were analyzed by real-time PCR using pairs of primers across the Not I sites. Initial DNA amounts were normalized against $\beta$-actin amount, as described above. The methylation ratio was defined as the proportion of undigested DNA in Not I-treated genome to that in Not Iuntreated genome. Primers for real-time PCR were as follows: spot U7: 5'-CAG GTG CTG CCC ACT GTC3', 5'-AAA AGA GAG CAA AGG AAA ACT TAG C-3'; and spot U10: 5'-GGC AGA ATG CTC AGG AAC AG-3', 5'-AGG TGA CAG GTG GCA AGA TT3'. Reactions were performed in triplicate using the same sample as in RLGS analysis. Data are presented as means \pm S.E.M.

\section{Statistical analysis}

Data are expressed as means \pm S.E.M. Statistical analyses were performed using Student's $t$-test with significance set at $\mathrm{p}<0.05$.

\section{Results}

\section{Effects on body and uterine weights}

DES-treated mice exhibited reduced body weights throughout the experiment (Table 1). Immediately after DES exposure, at day 5, body weights were reduced to $84.7 \%$ of control, and at day 14 , the reduction became the largest ( $71.9 \%$ of control). At day 30 , body weights of DES-treated mice were gradually 
Table 1. Body and uterine weights

\begin{tabular}{llccc}
\hline & & $\begin{array}{c}\text { Body weight } \\
(\mathrm{g})\end{array}$ & $\begin{array}{c}\text { Uterine weight } \\
(\mathrm{mg})\end{array}$ & $\begin{array}{c}\text { Relative uterine weight } \\
(\mathrm{mg} / \mathrm{g})\end{array}$ \\
\hline Day 5 & Control & $3.03 \pm 0.07$ & $\mathrm{ND}$ & $\mathrm{ND}$ \\
& DES & $2.56 \pm 0.05^{*}$ & $\mathrm{ND}$ & $\mathrm{ND}$ \\
\multirow{2}{*}{ Day 14} & Control & $6.08 \pm 0.17$ & $5.08 \pm 0.21$ & $0.84 \pm 0.02$ \\
& DES & $4.37 \pm 0.22^{* *}$ & $9.00 \pm 1.65^{*}$ & $2.06 \pm 0.36^{* *}$ \\
Day 30 & Control & $13.35 \pm 0.41$ & $17.04 \pm 1.83$ & $1.26 \pm 0.10$ \\
& DES & $11.20 \pm 0.82^{*}$ & $6.63 \pm 0.88^{* *}$ & $0.59 \pm 0.05^{* *}$ \\
\hline
\end{tabular}

ND indicates no data. ${ }^{*} p<0.05,{ }^{* *} p<0.01$ vs. control

restored to the control value ( $83.9 \%$ of control). There were no significant differences in the body weight between control and DES treated mice at birth. On the other hand, uterine weights were higher in DEStreated mice than in control mice at day 14 (177.3\% of control). However, thereafter, they were reduced to lower than control at day 30 (38.9\% of control).

\section{Expression of DNA methyltransferases and transcrip- tion factors}

Real-time RT-PCR revealed altered expressions of the DNA methyltransferases, Dnmt1, Dnmt3a, and Dnmt3b by DES treatment. In DES-treated mice, expressions of Dnmt1 and Dnmt3b were decreased at day 5, and those of Dnmt1 and Dnmt3a at day 14 (Fig. 1). Furthermore, expressions of transcription factors Sp1 and Sp3 were examined; at day 5, expression of Sp3 was decreased and at day 14, that of Sp1 was (Fig. 2). At day 30, expressions of Dnmts, Sp1, and Sp3 were not significantly different between treatments (Figs. 1 and 2).

\section{$R L G S$}

We performed RLGS to analyze methylation status of the uterus at day 30 with or without DES treatment. In this analysis, the presence of spots indicated demethylation of landmark Not I sites, and vice versa. A total of 1212 spots were compared to identify differences between control and DES-treated mice in the uterus. Five spots $(0.4 \%$ of all spots analyzed) were only detected in control mice (Fig. 3, U1-U5 in left panel), and another $5(0.4 \%)$ were specifically detected only in DES-treated mice (Fig. 3, U6-U10 in right panel). The remaining 1202 spots $(99.6 \%)$ were detected in both control and DES-treated mice.
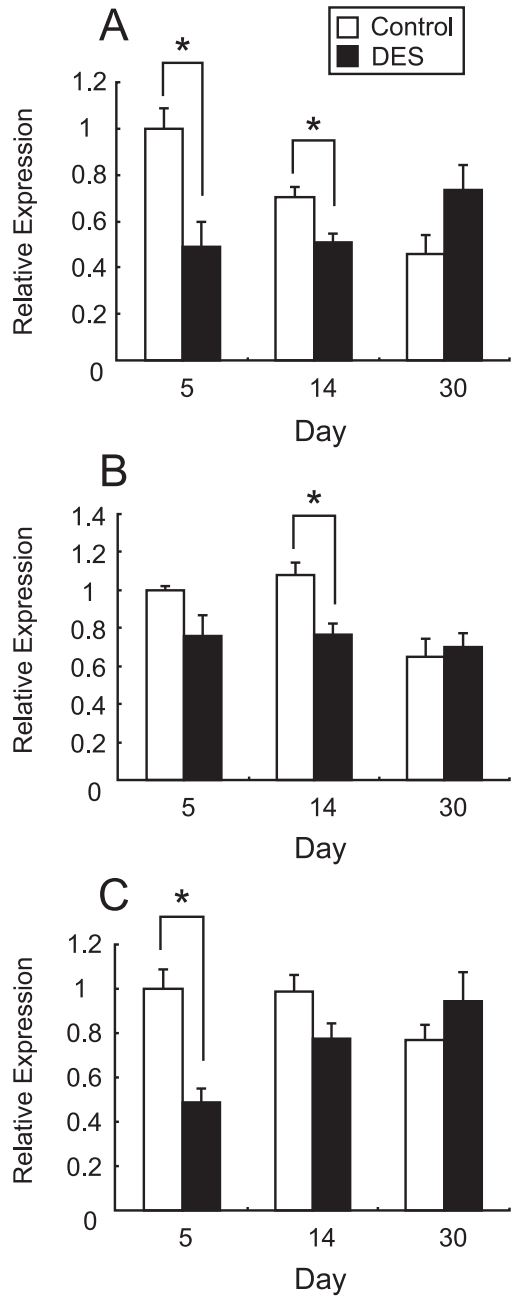

Fig. 1. Effects of diethylstilbestrol (DES) on mRNA expression levels of DNA methyltransferases. Newborn mice were exposed to DES from postnatal days 1 to 5 and expression levels of Dnmt1 (A), Dnmt3a (B), and Dnmt3b (C) in the uterus were examined by real-time RT-PCR. Expression of each gene in control mice at day 5 was normalized to 1 . Data are expressed as means \pm S.E.M. of 5 uteri. ${ }^{*} p<0.05$. 


\section{Spot Cloning}

We performed spot cloning using Easy Anchor Not I, and successfully cloned 2 spots, but could not clone
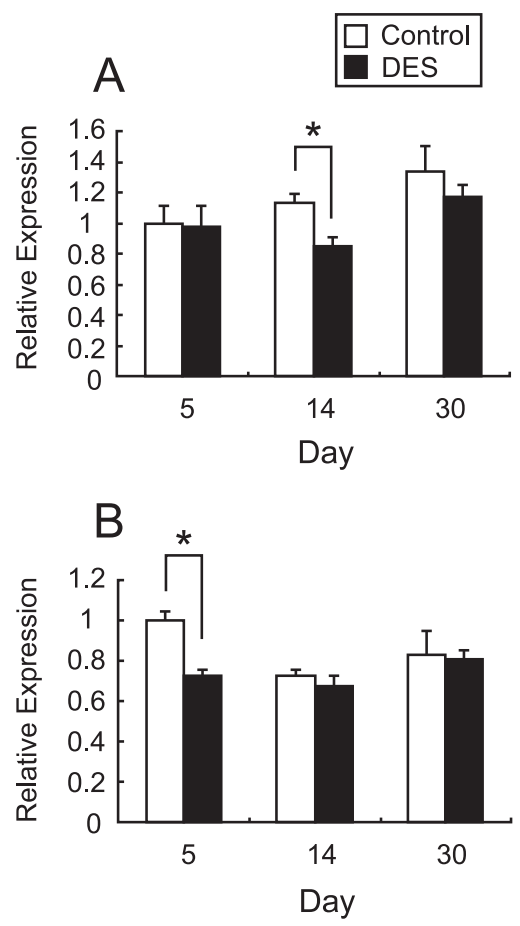

Fig. 2. Effects of diethylstilbestrol (DES) on mRNA expression levels of Sp1 and Sp3. The same sample as in Fig. 1 was used in this analysis. Expression levels of Sp1 (A) and Sp3 (B) in the uterus were examined by real-time RT-PCR. Expression of each gene in control mice at day 5 was normalized to 1 . Data are expressed as means \pm S.E.M. of 5 uteri. ${ }^{*} p<0.05$. the other 8 spots. Characteristics of the cloned DNA fragments including lengths of Not I-Pst I fragments, their genomic loci and neighboring genes, were identified using BLAST (http://www.ncbi.nlm.nih.gov/ BLAST/) (Table 2). Specifically, spot U7 was located in intron 1 of the paxillin gene. Spot U10 was located between hypothetical proteins LOC628639 and LOC628579, and the distances from them were about $180 \mathrm{~kb}$ and $210 \mathrm{~kb}$, respectively.

\section{Quantification of DNA methylation}

For the 2 cloned spots, differential methylation detected by RLGS was confirmed and quantified using methylation-sensitive restriction digestion and realtime PCR. As shown in Fig. 4, the methylation ratio of DES-treated mice was lower than that of control mice, in accordance with results of RLGS analysis. At spot U7, the methylation ratio of control mice was $48.5 \%$, while that of DES-treated mice was $36.0 \%$; and at spot U10, it was $56.8 \%$ in control mice, and $36.8 \%$ in DEStreated mice.

\section{Discussion}

Neonatal exposure to DES is reported to cause increase of uterine weight [30], decrease of body weight [31], and later in life, obesity [31] and uterine cancer [32]. One of the objectives of our work was to detect epigenetic changes in young mice to predict a

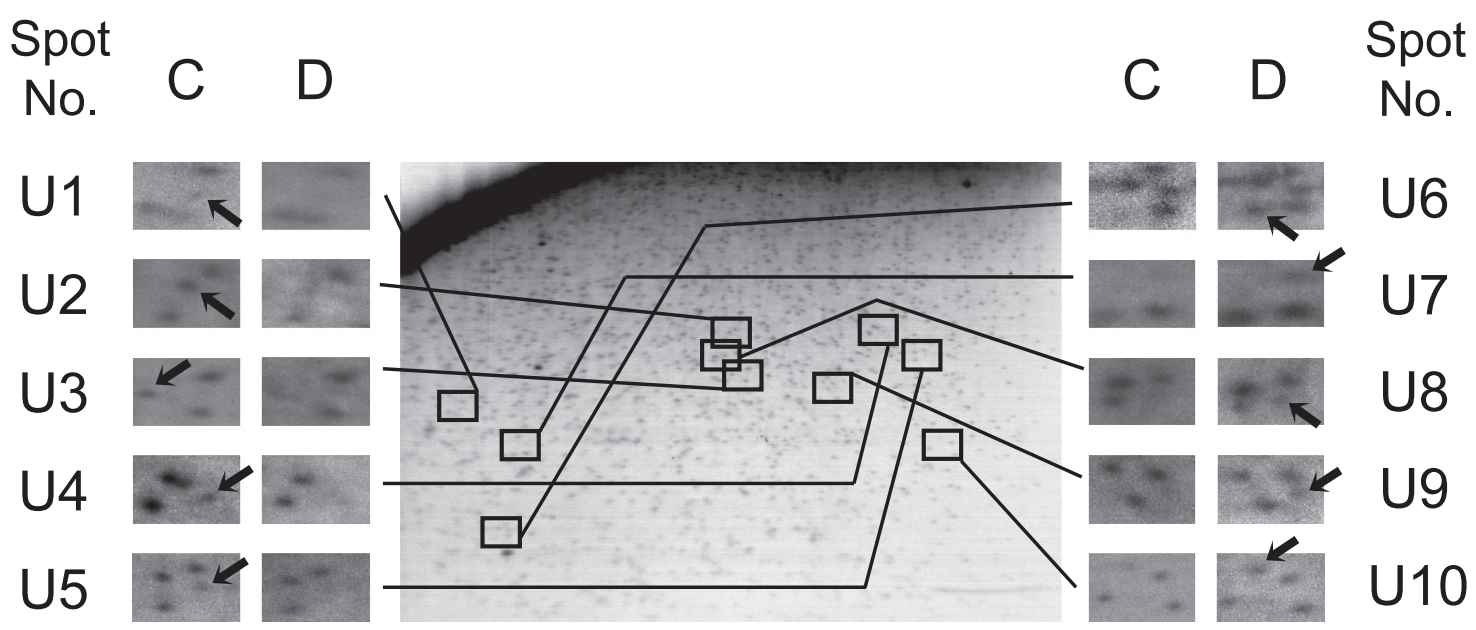

Fig. 3. Restriction landmark genomic scanning (RLGS) profiles of mouse uterus with and without DES treatment. Uterine genomic DNA samples from control and DES-treated mice were subjected to RLGS analysis. Each genomic DNA sample used was a pooled mixture of samples from 3 mice, and each experiment was repeated twice. Left and right panels show spots detected only in control (C) or DES-treated (D) mice. Arrows indicate different detected spots. 
Table 2. Characterization of cloned spots in uteri

\begin{tabular}{cccc}
\hline Spot no. & Length $(\mathrm{bp})$ & Locus & Gene \\
\hline U7 & 295 & $5 \mathrm{~F}$ & paxillin \\
U10 & 323 & $12 \mathrm{~A} 1.1$ & - \\
\hline
\end{tabular}
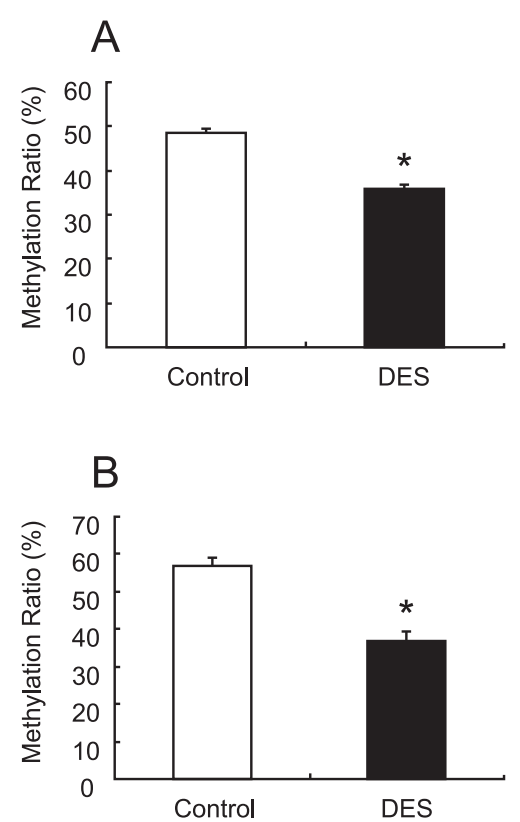

Fig. 4. Quantification of DNA methylation at landmark Not I sites of cloned spots. Genomic DNAs extracted from DES-treated and control mice were digested with Pst I. Subsequently, samples were subjected to real-time PCR with or without Not I digestion, using, pairs of primers across the Not I sites of spot U7 or U10. The methylation ratio was defined as the proportion of undigested DNA in the Not I-treated genome to that in the Not I-untreated genome. The upper panel (A) shows results of spot U7, and the lower (B) those of spot U10. $* p<0.05$.

future disease. In the present study, the alteration of body and uterine weights (Table 1) were similar to the previous study, and we analyzed the expression of Dnmts and DNA methylation. Our results indicated that DES exposure caused altered expressions of Dnmts at days 5 and 14, and aberrant DNA methylation of several genomic loci at day 30 in the uterus. As a result of DES-treatment, the expression of Dnmt1 decreased at days 5 and 14, whereas those of Dnmt3a and Dnmt3b decreased significantly only at days 14 or 5 , respectively, even though a decrease was also observed at both days.

It is important to elucidate why the expression levels of Dnmts were altered by DES. In some cases, envi- ronmental stresses can alter the expressions of Dnmts and Dnmt activity. For example, Raiche et al. reported that low-dose $\mathrm{X}$-irradiation altered the expression of Dnmts and DNA methylation in a sex- and tissue-specific manner, and the authors showed the association of estrogen [20]. Wu et al. indicated that exposure of mouse preimplantation embryos to 2,3,7,8tetrachlorodibenzo-p-dioxin (TCDD), which binds to the aryl hydrocarbon receptor (AhR), increased methylation levels of the imprinted genes $H 19$ and $\operatorname{Igf} 2$, and DNA methyltransferase activity [19]. AhR and estrogen receptor (ER) are members of the nuclear receptor superfamily, and crosstalk between AhR and ER has been reported [33]. The transcription factors Sp1 and Sp3 are reported to regulate expressions of Dnmt1, Dnmt3a, and Dnmt3b [21, 22]. It is further reported that expressions or activities of $\mathrm{Sp} 1$ and $\mathrm{Sp} 3$ are altered by environmental stimuli such as oxidative stress [34] or shear stress [35]. Effects of estradiol or DES are not clear, but the induction of Sp1 by the estrogen related receptor (ERR) $\alpha$ has been reported [36], while DES is an agonist of ERR $\alpha$ [37]. Furthermore, it is well known that Sp1 and ER cooperatively regulate the expressions of various genes. Exogenous estrogenic compounds might affect expression of Sp1 or Sp3.

In the present study, expressions of $\mathrm{Sp} 1$ and $\mathrm{Sp} 3$ were decreased at days 14 and 5, respectively, and this was consistent with decreased expressions of Dnmts. The reason why the effect on Sp3 appeared at day 5 and the effect on Sp1 did so later was not clear. Li et al. reported that neonatal exposure to DES altered the methylation of lactoferrin promoter in the mouse uterus at day 21 although it was not affected at day 17 [14]. There might be some mechanisms that induce delayed effects on DNA methylation. However, Sp1 and $\mathrm{Sp} 3$ are transcription factors regulating expressions of various genes with a GC box [23]. Further studies will be needed to elucidate whether a reduction in the levels of Dnmts in this study depended on reductions of the amounts of $\mathrm{Sp} 1$ or Sp3. In our previous study, the expressions of Sp1, Sp3 and DNA methyltransferases were increased in the epididymis by DES treatment [10], but in the current study, they were decreased in the uterus. Furthermore, in our previous studies and other reports, body and epididymis weights were decreased by DES treatment in male mice $[7,8$, $25,38]$, but in the current study using female mice, uterine weights were increased at day 14 although 
body weights were decreased. We think that it might come from the difference of the organs involved. It is well known that tamoxifen acts as antagonist of estrogen receptor in breast cancer, but as agonist in the uterus, and increases the risk of uterine cancer. It is thought that this tissue specificity is determined by the differences in the expressions of coregulators [39]. DES binds the estrogen receptor and the estrogen related receptor (ERR). In our previous study, the expression of ERR $\beta$ in the epididymis was increased remarkably by neonatal DES treatment (unpublished data), but in the uterus, it was not altered (data not shown). It is possible that ERR $\beta$ affected the expression of Sp1, Sp3 or Dnmts in the epididymis.

RLGS analysis revealed that 10 spots were different between control and DES-treated groups at day 30 . Unexpectedly, although expressions of Dnmts were decreased at days 5 and 14, the numbers of methylated and demethylated spots were the same (5 spots). This could be explained by the fact that $\mathrm{CpG}$ islands were mainly analyzed by RLGS using Not I as a landmark [40]. It is suggested that the genomic regions important for gene regulation, such as the $\mathrm{CpG}$ island, were protected from changes of DNA methylation [41]. Further analysis, including regions other than the $\mathrm{CpG}$ islands, might show decreased DNA methylation in the DES-treated group. In this study, a total of 10 spots out of 1200 (about $0.8 \%$ ) showed differences in appearance in the RLGS profiles. In previous studies using RLGS, the differences of spots among the different organs were only $1-3 \%$ [13, 27-29], and therefore, the alterations of DNA methylation observed in the present study were not small.

Spot U7 is located in intron 1 of the paxillin gene, and the distances from exon 1 and exon 2 are about $17 \mathrm{~kb}$ and $20 \mathrm{~kb}$, respectively. Although intron 1 includes a few $\mathrm{CpG}$ islands, there are $2 \mathrm{CpG}$ islands around spot U7 (about $200 \mathrm{bp}$ upstream and $100 \mathrm{bp}$ downstream). The relation between estrogen and paxillin is not clear, but there is a report that in the hypothalamus of neonatal female rat, esradiol administration reduced the expression of paxillin and affected the brain sexual differentiation [42]. On the other hand, there are no genes around spot 10. The GC content and the $\mathrm{CpG}$ frequency of spot 10 are low (49\% and 0.31 , respectively), and there are no $\mathrm{CpG}$ islands around it. In this study we could clone 2 spots, but failed to clone others because of technical difficulties. The amounts of DNA fragments obtained from the spots were extremely small, and there were a large quantity of hidden unlabeled DNA fragments around the spots. We either could not get any sequences, or could only obtain DNA fragments that were not Not IPst I sequences because of failure of ligation to the cloning vector. Combination with another cloning method such as virtual RLGS [43] or using a genomic DNA restriction fragment boundary library [44] ought to improve the efficiency of spot cloning, and should make more information about the spots available.

In the current study, we indicated that neonatal DES exposure induced altered expressions of Dnmts and related transcription factors as well as aberrant DNA methylation. DES is reported to be non-genotoxic [11] but may be epigenotoxic. Neonatal DES treatmentinduced uterine cancer is suspected to be associated with epigenetic alterations [14] and other various human diseases such as many forms of cancers, while immune and neuropsychiatric disorders are also thought to involve epigenetic alterations [45]. Recently, it has been proposed that when evaluating toxicities of endocrine disruptors and other chemicals, the epigenetic effects, such as DNA methylation, should be taken into account [46-48]. However, there is a lack of knowledge between exposure to chemicals and epigenetic alterations such as DNA methylation or chromatin modification. To elucidate this aspect it is important to determine the effects on the expressions of Dnmts, histone acetyltransferases, and histone deacetylases or methyltransferases. It may be that increased expression levels of Dnmts do not directly increase DNA methylation, and that DNA methylation might be altered without expression changes in Dnmts; however, altered expressions in Dnmts or histone modifying enzymes are doubtlessly essential factors inducing epigenetic alterations. Further studies on various chemicals inducing expression changes of such genes are important to elucidate the mechanisms of epigenetic changes; these might then be used in the development of drugs for diseases involving epigenetic disorders.

\section{Acknowledgements}

This work was supported by grants-in-aid for scientific research from the Ministry of Education, Science and Culture of Japan (Nos. 17201013, 17510041 and 17590148). 


\section{References}

1. Herbst AL, Ulfelder H, Poskanzer DC (1971) Adenocarcinoma of the vagina. Association of maternal stilbestrol therapy with tumor appearance in young women. N Engl J Med 284: 878-881.

2. Newbold RR (2004) Lessons learned from perinatal exposure to diethylstilbestrol. Toxicol Appl Pharmacol 199: 142-150.

3. McLachlan JA, Newbold RR, Bullock B (1975) Reproductive tract lesions in male mice exposed prenatally to diethylstilbestrol. Science 190: 991-992.

4. Iguchi T, Takase M, Takasugi N (1986) Development of vaginal adenosis-like lesions and uterine epithelial stratification in mice exposed perinatally to diethylstilbestrol. Proc Soc Exp Biol Med 181: 59-65.

5. Newbold R (1995) Cellular and molecular effects of developmental exposure to diethylstilbestrol: implications for other environmental estrogens. Environ Health Perspect 103.Suppl 7: 83-87.

6. Adachi T, Matsuno Y, Sugimura A, Takano K, Koh KB, Sakurai K, Shibayama T, Iguchi T, Mori C, Komiyama M (2003) ADAM7 (a disintegrin and metalloprotease 7) mRNA is suppressed in mouse epididymis by neonatal exposure to diethylstilbestrol. Mol Reprod Dev 64: 414-421.

7. Adachi T, Ono Y, Koh KB, Takashima K, Tainaka H, Matsuno Y, Nakagawa S, Todaka E, Sakurai K, Fukata H, Iguchi T, Komiyama M, Mori C (2004) Long-term alteration of gene expression without morphological change in testis after neonatal exposure to genistein in mice: toxicogenomic analysis using cDNA microarray. Food Chem Toxicol 42: 445-452.

8. Matsuno Y, Adachi T, Koh KB, Fukata H, Sugimura A, Sakurai K, Shibayama T, Iguchi T, Komiyama M, Mori C (2004) Effect of neonatal exposure to diethylstilbestrol on testicular gene expression in adult mouse: comprehensive analysis with cDNA subtraction method. Int J Androl 27: 115-122.

9. Shibayama T, Fukata H, Sakurai K, Adachi T, Komiyama M, Iguchi T, Mori C (2001) Neonatal exposure to genistein reduces expression of estrogen receptor alpha and androgen receptor in testes of adult mice. Endocr J 48: 655-663.

10. Sato K, Fukata H, Kogo Y, Ohgane J, Shiota K, Mori C (2006) Neonatal exposure to diethylstilbestrol alters the expression of DNA methyltransferases and methylation of genomic DNA in the epididymis of mice. Endocr $J$ 53: 331-337.

11. Cunningham A, Klopman G, Rosenkranz HS (1996) The carcinogenicity of diethylstilbestrol: structural evidence for a non-genotoxic mechanism. Arch Toxicol 70: 356-361.

12. Shiota K, Yanagimachi R (2002) Epigenetics by DNA methylation for development of normal and cloned animals. Differentiation 69: 162-166.

13. Shiota K, Kogo Y, Ohgane J, Imamura T, Urano A, Nishino K, Tanaka S, Hattori N (2002) Epigenetic marks by DNA methylation specific to stem, germ and somatic cells in mice. Genes Cells 7: 961-969.

14. Li S, Washburn KA, Moore R, Uno T, Teng C, Newbold RR, McLachlan JA, Negishi M (1997) Developmental exposure to diethylstilbestrol elicits demethylation of estrogen-responsive lactoferrin gene in mouse uterus. Cancer Res 57: 4356-4359.

15. Li S, Hansman R, Newbold R, Davis B, McLachlan JA, Barrett JC (2003) Neonatal diethylstilbestrol exposure induces persistent elevation of c-fos expression and hypomethylation in its exon-4 in mouse uterus. Mol Carcinog 38: 78-84.

16. Alworth LC, Howdeshell KL, Ruhlen RL, Day JK, Lubahn DB, Huang TH, Besch-Williford CL, vom Saal FS (2002) Uterine responsiveness to estradiol and DNA methylation are altered by fetal exposure to diethylstilbestrol and methoxychlor in CD-1 mice: effects of low versus high doses. Toxicol Appl Pharmacol 183: 10-22.

17. Leonhardt H, Page AW, Weier HU, Bestor TH (1992) A targeting sequence directs DNA methyltransferase to sites of DNA replication in mammalian nuclei. Cell 71: 865-873.

18. Okano M, Xie S, Li E (1998) Cloning and characterization of a family of novel mammalian DNA (cytosine-5) methyltransferases. Nat Genet 19: 219-220.

19. Wu Q, Ohsako S, Ishimura R, Suzuki JS, Tohyama C (2004) Exposure of mouse preimplantation embryos to 2,3,7,8-tetrachlorodibenzo-p-dioxin (TCDD) alters the methylation status of imprinted genes $\mathrm{H} 19$ and $\mathrm{Igf} 2$. Biol Reprod 70: 1790-1797.

20. Raiche J, Rodriguez-Juarez R, Pogribny I, Kovalchuk $\mathrm{O}$ (2004) Sex- and tissue-specific expression of maintenance and de novo DNA methyltransferases upon low dose X-irradiation in mice. Biochem Biophys Res Commun 325: 39-47.

21. Kishikawa S, Murata $T$, Kimura $H$, Shiota $K$, Yokoyama KK (2002) Regulation of transcription of the Dnmt1 gene by Sp1 and Sp3 zinc finger proteins. Eur J Biochem 269: 2961-2970.

22. Jinawath A, Miyake S, Yanagisawa Y, Akiyama Y, Yuasa Y (2005) Transcriptional regulation of the human DNA methyltransferase 3A and 3B genes by Sp3 and Sp1 zinc finger proteins. Biochem J 385: $557-$ 564.

23. Li L, He S, Sun JM, Davie JR (2004) Gene regulation by Sp1 and Sp3. Biochem Cell Biol 82: 460-471.

24. Yamazaki K, Adachi T, Sato K, Yanagisawa Y, Fukata 
H, Seki N, Mori C, Komiyama M (2006) Identification and characterization of novel and unknown mouse epididymis-specific genes by complementary DNA microarray technology. Biol Reprod 75: 462-468.

25. Adachi T, Koh KB, Tainaka H, Matsuno Y, Ono Y, Sakurai K, Fukata H, Iguchi T, Komiyama M, Mori C (2004) Toxicogenomic difference between diethylstilbestrol and 17beta-estradiol in mouse testicular gene expression by neonatal exposure. Mol Reprod Dev 67: 19-25.

26. La Salle S, Mertineit C, Taketo T, Moens PB, Bestor TH, Trasler JM (2004) Windows for sex-specific methylation marked by DNA methyltransferase expression profiles in mouse germ cells. Dev Biol 268: 403-415.

27. Ohgane J, Aikawa J, Ogura A, Hattori N, Ogawa T, Shiota K (1998) Analysis of CpG islands of trophoblast giant cells by restriction landmark genomic scanning. Dev Genet 22: 132-140.

28. Ohgane J, Wakayama T, Kogo Y, Senda S, Hattori N, Tanaka S, Yanagimachi R, Shiota K (2001) DNA methylation variation in cloned mice. Genesis 30: 4550.

29. Imamura $\mathrm{T}$, Ohgane $\mathrm{J}$, Ito $\mathrm{S}$, Ogawa $\mathrm{T}$, Hattori $\mathrm{N}$, Tanaka S, Shiota K (2001) CpG island of rat sphingosine kinase-1 gene: tissue-dependent DNA methylation status and multiple alternative first exons. Genomics 76: 117-125.

30. Newbold RR, Padilla-Banks E, Jefferson WN (2006) Adverse effects of the model environmental estrogen diethylstilbestrol are transmitted to subsequent generations. Endocrinology 147: S11-17.

31. Newbold RR, Padilla-Banks E, Snyder RJ, Phillips TM, Jefferson WN (2007) Developmental exposure to endocrine disruptors and the obesity epidemic. Reprod Toxicol 23: 290-296.

32. Newbold RR, Bullock BC, McLachlan JA (1990) Uterine adenocarcinoma in mice following developmental treatment with estrogens: a model for hormonal carcinogenesis. Cancer Res 50: 7677-7681.

33. Ohtake F, Takeyama K, Matsumoto T, Kitagawa H, Yamamoto Y, Nohara K, Tohyama C, Krust A, Mimura J, Chambon P, Yanagisawa J, Fujii-Kuriyama Y, Kato S (2003) Modulation of oestrogen receptor signalling by association with the activated dioxin receptor. Nature 423: 545-550.

34. Ryu H, Lee J, Zaman K, Kubilis J, Ferrante RJ, Ross BD, Neve R, Ratan RR (2003) Sp1 and Sp3 are oxidative stress-inducible, antideath transcription factors in cortical neurons. J Neurosci 23: 3597-3606.

35. Lin MC, Almus-Jacobs F, Chen HH, Parry GC, Mackman N, Shyy JY, Chien S (1997) Shear stress induction of the tissue factor gene. J Clin Invest 99: 737-744.
36. Sumi D, Ignarro LJ (2005) Sp1 transcription factor expression is regulated by estrogen-related receptor alpha1. Biochem Biophys Res Commun 328: 165-172.

37. Shigeta H, Zuo W, Yang N, DiAugustine R, Teng CT (1997) The mouse estrogen receptor-related orphan receptor alpha 1: molecular cloning and estrogen responsiveness. J Mol Endocrinol 19: 299-309.

38. Warita K, Sugawara T, Yue ZP, Tsukahara S, Mutoh K, Hasegawa Y, Kitagawa H, Mori C, Hoshi N (2006) Progression of the dose-related effects of estrogenic endocrine disruptors, an important factor in declining fertility, differs between the hypothalamo-pituitary axis and reproductive organs of male mice. $J$ Vet Med Sci 68: 1257-1267.

39. Shang Y, Brown M (2002) Molecular determinants for the tissue specificity of SERMs. Science 295: 23802381.

40. Lindsay S, Bird AP (1987) Use of restriction enzymes to detect potential gene sequences in mammalian DNA. Nature 327: 336-338.

41. Ushijima T, Okochi-Takada E (2005) Aberrant methylations in cancer cells: where do they come from? Cancer Sci 96: 206-211.

42. Speert DB, Konkle AT, Zup SL, Schwarz JM, Shiroor C, Taylor ME, McCarthy MM (2007) Focal adhesion kinase and paxillin: novel regulators of brain sexual differentiation? Endocrinology 148: 3391-3401.

43. Matsuyama T, Kimura MT, Koike K, Abe T, Nakano T, Asami T, Ebisuzaki T, Held WA, Yoshida S, Nagase $\mathrm{H}$ (2003) Global methylation screening in the Arabidopsis thaliana and Mus musculus genome: applications of virtual image restriction landmark genomic scanning (Vi-RLGS). Nucleic Acids Res 31: 44904496.

44. Smiraglia DJ, Fruhwald MC, Costello JF, McCormick SP, Dai Z, Peltomaki P, O'Dorisio MS, Cavenee WK, Plass C (1999) A new tool for the rapid cloning of amplified and hypermethylated human DNA sequences from restriction landmark genome scanning gels. Genomics 58: 254-262.

45. Rodenhiser D, Mann M (2006) Epigenetics and human disease: translating basic biology into clinical applications. CMAJ 174: 341-348.

46. Watson RE, Goodman JI (2002) Epigenetics and DNA methylation come of age in toxicology. Toxicol Sci 67: 11-16.

47. Fukata H, Mori C (2004) Epigenetic alteration by the chemical substances, food and environmental factors. Reprod Med Biol 3: 115-121.

48. Reamon-Buettner SM, Borlak J (2007) A new paradigm in toxicology and teratology: Altering gene activity in the absence of DNA sequence variation. Reprod Toxicol 24: 20-30. 